\begin{tabular}{l}
\hline Jurnal Pakarena \\
Volume 5 Nomor 1, Juli 2020 \\
e-ISSN: 2550-102X dan p-ISSN: 1693-3990 \\
\begin{tabular}{|l|l|}
\hline (1) TAKARENA \\
\hline ar
\end{tabular} This work is licensed under a Creative Commons Attribution \\
\hline
\end{tabular}

\title{
Revitalisasi Tari Patu'du' Kumba Oleh Sanggar Seni Uwake' Di Kecamatan Tinambung Kabupaten Polewali Mandar
}

\section{Radawati, Rahma M, Andi Padalia}

Keywords :

Revitalisasi; Pattu'du'

Kumba; Uwake'; Mandar

\section{Corespondensi Author}

Seni Pertunjukan, Universitas

Negeri Makassar, Fakultas Seni dan

Desain Jln. Dg. Tata Kampus UNM

Parangtambung

rahma.m@unm.ac.id

fsdunm_padalia@yahoo.com

\author{
Artikel \\ Received: 03-Februari-2020; \\ Reviewed: 14-Juni-2020 \\ Revised: 01-Juli-2020 \\ Accepted: 02-Juli-2020 \\ Published: 06-Juli-2020
}

\begin{abstract}
Abstrak
Penelitian ini menjawab masalah yang ada selama proses Revitalisasi Pattu'du' Kumba yang dilakukan oleh Sanggar Seni Uwake' yaitu : (1) Bagaimana Proses Revitalisasi Pattu'du' Kumba oleh Sanggar Seni Uwake' di Kecamatan Tinambung Kabupaten Polewali Mandar, (2) Faktor apa yang mempengaruhi Revitalisasi Pattu'du' Kumba oleh Sanggar Seni Uwake' di Kecamatan Tinambung Kabupaten Polewali Mandar. Teknik pengumpulan data yang dipakai adalah: (1) Studi Pustaka yang diperoleh adalah dokumen-dokumen, dan buku-buku. (2) Observasi yang dilakukan adalah dengan cara melihat langsung situasi dan kondisi Sanggar Seni Uwake' yang merevitalisasi Tari Pattu'du' Kumba. (3) Wawancara dilakukan dengan beberapa narasumber yaitu Bapak Ahmad Asdy, Bapak H Alimuddin, Bapak M Rahmat Muchtar, Bapak Muhammad Ridwan Alimuddin, Ibu Siti Adila, dan Bapak Muh Naim Sail. (4) Dokumentasi yang diperoleh adalah berupa foto-foto, video serta rekaman hasil wawancara dengan beberapa Narasumber. Analisis data dilakukan dengan pendekatan Kualitatif sesuai dengan permasalah yang ada.

Objek penelitian adalah Tari Pattu'du' Kumba. Hasil dari penelitian ini yaitu: (1) Proses Revitalisasi Pattu'du' Kumba oleh Sanggar Seni Uwake' di Kecamatan Tinambung Kabupaten Polewali Mandar dilakukan dengan cara mengajak anak-anak anggota sanggar untuk mengikuti kegiatan yang bersifat kesenian tradisional, mulai dari berbagai workshop dan dipertontonkan video pertunjukan bersama-sama. Selain itu, proses revitalisasi juga dilakukan dengan tahapan memperkenalkan kembali Tari Pattu'du' Kumba terhadap anggota Sanggar, kemudian setelah mereka mengetahui hal Tentang Tari Pattu'du' Kumba mereka dibuatkan jadwal untuk latihan minimal sekali atau dua kali latihan agar pada saat dipentaskan penari tidak kaku dalam bergerak. Anggota Sanggar yang direkrut adalah siswasiswi pelajar SMP dan SMA. Wujud gerak yang mengalami perubahan adalah pada Ragam Mioro' Mi'undur (2) Revitalisasi Pattu'du'Kumba didukung oleh dua faktor yaitu faktor pendukung dan penghambat, hal tentang faktor pendukungnya adalah ketersediaan SDM, dukungan dari para Tokoh Budayawan serta masyarakat setempat, dukungan dari pemerintah berupa sarana untuk pertunjukan serta pengadaan alat musik untuk Sanggar Seni Uwake'. Faktor penghambat selama proses Revitalisasi adalah kurang ketersediaan waktu oleh para anggota sehingga pada saat jadwal latihan tidak jarang ada beberapa penari atau pemusik yang berhalangan hadir, tidak adanya baju dan perhiasan Pattu'du' Kumba yang dimiliki oleh Sanggar sehingga pada saat tari akan dipentaskan mereka harus menyewa kostum dari luar.
\end{abstract}

\footnotetext{
Abstract

This research answers the problems that exist during the revitalization process of Pattu'du' Kumba conducted by the Art
} 
Radawati, Rahma M, Andi Padalia. Revitalisasi Tari Patu'du' Kumba Oleh Sanggar Seni Uwake' Di Kecamatan Tinambung Kabupaten Polewali Mandar.

Gallery of Uwake' namely: (1) How is the process of revitalizing Pattu'du ' Kumba by the Art Gallery Uwake' in the district of Tinambung Polewali Mandar, (2) What factors influence the revitalization of Pattu'du 'Kumba by the Art Gallery Uwake 'in the district of Tinambung Polewali Mandar. The data collection techniques used are: (1) The library studies obtained are documents, and books. (2) The observation is by looking at the situation and condition of the art Gallery Uwake' which revitalizes the dance Pattu'du ' Kumba. (3) The interview was conducted with several speakers, Mr. Ahmad Asdy, Mr. H Alimuddin, Mr. M Rahmat Muchtar, Mr. Muhammad Ridwan Alimuddin, Ibu Siti Adila, and Mr. Muh Naim Sail. (4) The documentation obtained is in the form of photographs, videos and recordings of interviews with some speakers. Data analysis is done with qualitative approach according to the existing problem.

The research object is Dance Pattu'du 'Kumba. The results of this study are: (1) The revitalization process of Pattu'du ' Kumba by Sanggar Seni Uwake 'in the district of Tinambung Polewali Mandar is done by inviting children of the members to join the activities of art Traditional, ranging from workshops and displayed video performances together. In addition, the revitalization process is also done with the stage of reintroducing dance Pattu'du 'Kumba to the members of the Sanggar, then after they know the thing about dance Pattu'du 'Kumba They are made schedule for training at least once or Twice the exercises so that the dancers performed are not stiff in motion. Members of Sanggar recruited are students of JUNIOR and senior high school students. The form of motion that has changed is in the Variety Mioro ' Mi'undur (2) Revitalizing Pattu'du ' Kumba supported by two factors namely supporting and inhibiting factor, the thing about the supporting factors are the availability of human resources, the support of the people of Budayawan As well as local communities, support from the Government in the form of a vehicle for performances and procurement of musical instruments for Uwake Art Gallery. The inhibitory factor during the revitalization process is less time availability by the members so that when the training schedule is not uncommon there are some dancers or musicians who are absent, absent clothes and jewellery pattu'du ' Kumba Owned by Sanggar so that at the time of dance will be performed they have to rent costumes from outside.

\section{PENDAHULUAN}

\section{A. Latar Belakang}

Indonesia adalah negeri kepulauan yang memiliki banyak suku bangsa. Setiap suku bangsa memiliki kebudayaan yang menjadi karakteristik dari suku bangsa. Kebiasaan yang sudah mendarah daging dan bersifat turun temurun dalam suku bangsa itu dianggap kebudayaan. Kebudayaan di Indonesia masing-masing mengandung nilai-nilai budaya yang cukup tinggi. Nilai-nilai yang dimilki bangsa Indonesia inilah yang dapat membedakan bangsa Indonesia dengan bangsa lainnya. Banyak negara di dunia yang kagum pada kebudayaan Indonesia. Untuk itu warga
Indonesia dihimbau untuk melestarikan keberadaan budaya yang telah dimiliki.

Sebagai generasi penerus bangsa budaya kita berkewajiban untuk menjaga dan melestarikan budaya kita salah satunya adalah tari tradisional yang ada di negeri kita. Setiap daerah di Indonesia memilki tarian khas, salah satunya di Polewali Mandar. Polewali Mandar adalah salah satu nama Provinsi yang terdapat di Sulawesi Barat dan nama budaya dalam Lembaga Budayawan Nasional dan Lembaga Pengkajian budaya nasional diistilahkan sebagai etnis karena Mandar merupakan salah satu kelompok etnis dari empat suku yang mendiami kawasan Provinsi Sulawesi 
Jurnal Pakarena, Vol 4 No 1, Juli 2020, hlm 14-26.

Selatan yakni etnis Makassar (Mangkasara'), etnis Bugis (ogi'), dan etnis Toraja (Toraya). Pengelompokan ini dimaksudkan dalam kelompok "Lagaligo" di Polewali Mandar terdapat beberapa kesenian salah satunya adalah tari Pattu' $d u$ ' Kumba.

Tari Pattu'du' Kumba adalah salah satu tarian tradisional yang berasal dari Sulawesi Barat. Tarian ini biasanya dibawakan oleh para penari wanita dengan gerakannya yang lemah gemulai dengan menggunakan kipas dan selendang sebagai propertinya menari. Tarian Pattu'du' Kumba merupakan salah satu tarian tradisional yang cukup terkenal di Sulawesi Barat.

Asal usul Tari Pattu'du' Kumba itu sendiri adalah pada saat Islam belum memasuki daerah Mandar dulunya Pattu'du' Kumba ini adalah sebuah tari persembahan bagian dari ritual pada saat diadakannya pemujaan-pemujaan terhadap roh nenek moyang di daerah Mandar, tidak ada yang mengetahui pencipta Tari Pattu'du' Kumba yang sebenarnya. Setelah pergantian masuknya zaman Kerajaan di Mandar maka Tari Pattu'du' Kumba ini bukan lagi menjadi tari persembahan upacara pemujaan roh nenek moyang melainkan menjadi salah satu bagian dari pelaksanaan upacara kerajaan, gerakangerakannyapun dimaknai sebagai penghormatan atau penghargaan dan kepatuhan serta ketaatan kepada Raja. Tari Pattu'du' Kumba terus berkembang dalam perkembangannya sosok yang bernama Karaeng Surya yang berperan penting dalam tarian ini. Karaeng Surya adalah orang Makassar yang pertamakali membina Tari Pattu'du' Kumba tetapi bukan berarti beliau adalah pencipta Tari Pattu'du' Kumba itu sendiri, sehingga persamaan tari Mandar dan Makassar tidak jauh berbeda karena yang melatih tari Pattu'du' Kumba adalah orang Makassar. Tapi dapat digaris bawahi bahwa tarian ini bukan diambil dari Tari Makassar melainkan hasil dari kolaborasi tari persembahan itu sendiri dengan Karaeng Surya sehingga di dalam syair tarian terdapat kata Aule atau Lee yang dulunya tidak ada dalam syair tarian $(\mathrm{H}$. Ahmad Asdy, J1 Sultan Hasanuddin: 02 September 2019).

Mengingat tari Pattu'du' Kumba telah jarang ditampilkan karena tarian ini hanya ditampilkan pada acara-acara kerajaan seperti Pelantikan Raja, Pelattigiang (Malam Pacar), Khitanan, Pernikahan anakanak Raja. Tari Pattu'du' Kumba terakhir ditampilkan pada upacara Pelantikan Raja/Pemangku Adat ke 55 Andi Bau Arifin Malik yaitu pada tahun 2008. Kurang lebih 10 Tahun Tari Pattu'du' Kumba tidak diampilkan, maka sanggar seni Uwake' berinisiatif untuk memperkenalkan kembali tarian ini dengan cara merevitalisasi kembali tari Pattu'du' Kumba dengan tujuan menghidupkan kembali tarian ini agar generasi-generasi selanjutnya tidak kehilangan jejak tari Pattu'du' Kumba. Proses revitalisasi Pattu'du' Kumba yang dilakukan oleh Sanggar Seni Uwake, dimulai pada tahun 2016, kemudian pada tanggal 2-4 Oktober 2017 Tari Pattu'du' Kumba mulai ditampilkan kembali di Festival Pesona Cakuriri di Sendana Kabupaten Maje'ne setelah kurang lebih 10 tahun tarian ini tidak ditampilkan. Revitalisasi dalam Kamus Besar Bahasa Indonesia memiliki arti yaitu proses, cara, perbuatan menghidupkan kembali berbagai kegiatan kesenian tradisional.

Sanggar Seni Uwake' Culture Foundation atau sanggar Seni Uwake' adalah sebuah lembaga nirlaba yang sejak tahun 2010 telah lahir dan baru tahun 2012 kehadirannya sudah resmi diakta notariskan, ketua pertama sanggar seni Uwake' adalah M. Rahmat Muchtar yang masih penjabat sampai saat ini. Sanggar seni Uwake' mencoba melakukan penguatan kehidupan serta programprogram pengembangan sumber daya manusia dalam bidang pendidikan, pelestarian melalui perspektif seni budaya baik yang berasal dari pemerintahan, swasta dan masyrakat. Penamaan "Uwake" pada sanggar seni Uwake' berasal dari bahasa 
Radawati, Rahma M, Andi Padalia. Revitalisasi Tari Patu'du' Kumba Oleh Sanggar Seni Uwake' Di Kecamatan Tinambung Kabupaten Polewali Mandar.

Mandar yang berarti "akar" maka dari itu dalam berkesenian sanggar ini tetap menjujung tinggi yang dikatakan budaya dan tradisi yang ditinjaudari akarnya atau dapat dikatakan keaslian dari kesenian itu sendiri (Wawancara, M. Rahmat Muhtar, J1 Sultan Hasanuddin, 4 November 2019).

\section{B. Rumusan Masalah}

Berdasarkan latar belakang di atas maka untuk menghindari timbulnya salah pengertian yang terlalu jauh terhadap masalah yang diteliti maka dikemukakan rumusan dari masalah sebagai berikut:

1. Bagaimana proses revitalisasi Tari Pattu'du' Kumba oleh Sanggar Seni Uwake' di Kecamatan Tinambung Kabupaten Polewali Mandar?

2. Apa faktor yang mempengaruhi proses Revitalisasi Tari Pattu'du' Kumba oleh Sanggar Seni Uwake' di Kecamatan Tinambung Kabupaten Polewali Mandar.

\section{Tujuan Penelitian}

Setiap penelitian harus lebih dahulu adanya tujuan penelitinan, sebab hanya dengan mengetahui tujuan itu peneliti maupun pembaca dapat mengarahkan pemikirannya serta dapat menempatkan uraian-uraian itu dalam proposal yang wajar.

Berdasarkan rumusan masalah di atas pelaksanaan penelitian ini diharapkan untuk mendapatkan data dan informasi yang jelas lengkap dan benar tentang revitalisasi Tari Pattu'du' Kumba oleh Sanggar Uwake' di Kecamatan Tinambung Kabupaten Polewali Mandar. Adapun tujuan penelitiannya adalah sebagai berikut:

1. Untuk mendeskripsikan proses Revitalisasi Tari Pattu'du' Kumba di Sanggar Seni Uwake' di Kecamatan Tinambung Kabupaten Polewali Mandar.

2. Untuk mendeskripsikan faktor apa saja yang mempengaruhi proses Revitalisasi Tari Pattu'du' Kumba oleh Sanggar seni Uwake' di
Kecamatan Tinambung Kabupaten Polewali Mandar

\section{Manfaat Penelitian}

Penelitian ini diharapkan dapat bermanfaat untuk:

1. Sebagai bahan pengetahuan kepada masyarakat Mandar dan generasi muda mengenai Tari Pattu'du' Kumba.

2. Sebagai sumbang pikiran atau informasi bagi masyarakat luas atau mahasiswa seni untuk mengenal tari Pattu'du' Kumba dan diharapkan dapat mengembangkan serta melestarikan tarian tersebut.

3. Untuk mengembangkan dan memperkaya wawasan dunia ilmu pengetahuan khususnya dalam bidang seni tari terhadap kebudayaan kita pada umumnya.

4. Sebagai bahan referensi untuk peneliti berikutnya khusunya bagi mahasiswa Seni Tari di Universitas Negeri Makassar.

5. Penelitian ini dapat dijadikan sebagai bahan penelitian selanjutnya jika ada yang ingin melengkapi kekurangan atau hal-hal penting tentang Tari Pattu'du' Kumba di Kecamatan Tinambung Kabupaten.

\section{METODE PENELITIAN}

\section{A. Jenis Penelitian}

Pada penelitian ini, peneliti memilih jenis penelitian kualitatif yaitu data yang ditampilkan berupa kata-kata dan bukan angka-angka. Dalam bukunya Halilintar Latief mengatakan bahwa penelitian kualitatif adalah penelitian eksplorasi yang biasanya lebih bersifat studi kasus. Jenis penelitian ini mempunyai proses pada penelitian kualitatif. Data penelitian kualitatif merupakan teori atau teori berdasarkan data. Kategori-kategori dan konsep-konsep yang dikembangkan oleh peneliti di lapangan (Latief, 2016: 39) 
Jurnal Pakarena, Vol 4 No 1, Juli 2020, hlm 14-26.

\section{B. Desain Penelitian}

Desain penelitian adalah proses yang diperlukan dalam perencanaan dan pelaksanaan penelitian untuk memperjelas Revitalisasi Tari Pattu'du' Kumba oleh Sanggar Seni Uwake' di Kecamatan Tinambung Kabupaten Polewali Mandar.

1. Memberi pegangan tentang cara pelaksanaan penelitian.

2. Menentukan batas-batas penelitian.

3. Memberi gambaran tentang apa yang dilakukan serta kesulitan yang akan dihadapi.

\section{Sasaran dan Responden}

\section{Sasaran}

Sasaran merupakan sesuatu yang ingin dicapai oleh individu, sasaran juga sering disebut tujuan, sasaran dalam penelitian ini untuk mengetahui Revitalisasi Tari Pattu'du' Kumba Oleh Sanggar Seni Uwake' di Kecamatan Tinambung Kabupaten Polewai Mandar, serta mampu menjawab permasalahan yang ada pada penelitian ini yaitu bagaimana proses Rivitalisasi Tari Pattu'du' Kumba oleh Sanggar Seni Uwake' dan faktor apa saja yang mempengaruhi proses Revitalisasi Tari Pattu'du' Kumba oleh Sanggar Seni Uwake'.

\section{Responden}

Responden merupakan jawaban atas pertanyaan yang diajukan untuk kepentingan peneliti. Responden yang dimaksudkan di sini adalah jawabanjawaban dari Narasumber yang diwawancarai tentang Revitalisasi Tari Pattu'du' Kumba Oleh Sanggar Seni Uwake' di Kecamatan Tinambung Kabupaten Polewali.

\section{Teknik Pengumpulan Data}

Tehnik pengumpulan data dilakukan untuk memperoleh informasi yang dibutuhkan dalam rangka mencapai tujuan penelitian dan untuk mendapatkan data yang akurat tentang Revitalisasi Tari Pattu'du' Kumba Oleh Sanggar Seni
Uwake' di Kecamatan Tinambung Kabupaten Polewali, adapun teknik yang digunakan peneliti dalam mengumpulkan data adalah sebagai berikut:

\section{Studi Pustaka}

Studi pustaka bertujuan untuk memperoleh data atau informasi yang diperlukan dari berbagai sumber bacaan baik bersifat dokumen, buku-buku dan naskah tertulis lainnya yang relevan untuk menguatkan data yang diperoleh dari sumber-sumber lain seperti wawancara, observasi dan lain-lain dengan permasalahan yang terkait dengan Tari Pattu'du' Kumba.

Adapun tujuan dari studi pustaka yaitu:

a. Untuk mengetahui apakah topik penelitian kita telah diteliti orang lain sebelumnya, sehingga penelitian kita tidak merupakan duplikasi.

b. Untuk mengetahui hasil penelitian orang lain dalam bidang yang sama sehingga kita dapat memanfaatkannya untuk penelitian kita.

c. Untuk memperoleh bahan yang mempertajam orientasi dan dasar teoritis kita tentang masalah penelitian kita.

d. Untuk memperoleh informasi tentang tehnik penelitian telah diterapkan.

\section{Observasi}

Observasi adalah hal yang pertama dilakukan dengan mengadakan peninjauan terhadap objek penelitian Revitalisasi Tari Pattu'du' Kumba oleh Sanggar Seni Uwake' di Kecamatan Tinambung Kabupaten Polewali guna mendapatkan data tambahan sekiranya data yang ditambahkan belum jelas.

Teknik observasi ini dilakukan untuk mengetahui kebenaran objek yang diteliti. Adapun observasi yang dilakukan adalah dengan cara melihat langsung situasi dan kondisi Sanggar Seni Uwake' yang telah merevitalisasi tari Pattu'du' Kumba serta melihat dokumen-dokumen yang ada pada sanggar. 
Radawati, Rahma M, Andi Padalia. Revitalisasi Tari Patu'du' Kumba Oleh Sanggar Seni Uwake' Di Kecamatan Tinambung Kabupaten Polewali Mandar.

\section{Wawancara}

Wawancara menurut Moleong (2006: 135) adalah percakapan dengan maksud tertenrtu yang melibatkan dua belah pihak, yaitu pewawancara (interview) yang mengajukan pertanyaan dan terwawancara (interviewee) yang memberikan jawaban atas pertanyaan. Melalui teknik wawancara peneliti telah melakukan wawancara dengan beberapa narasumber yaitu dengan Muh. Naim Sail dan ketua Sanggar Seni Uwake' yaitu M. Rahmat Muchtar. Selain kedua responden tersebut tanya jawab juga dilakukan dengan beberapa responden yang dianggap memahami dan mengerti masalah yang ingin diteliti dengan tujuan memperoleh keterangan mengenai Revitalisasi Tari Pattu'du' Kumba oleh Sanggar Seni Uwake' di Kecamatan Tinambung Kabupaten Polewali Mandar.

Ada beberapa Narasumber yang diwawancarai oleh peneliti dengan garis besar wawancaara yang berbeda-beda yaitu

- Ahmad Asdy (Penulis Tokoh Budaya), melalui narasumber ini, Peneliti mendapatkan banyak informasi tentang sejarah Pattu'du' Kumba dan sejarah Kerajaan Balanipa. Bapak Ahmad Asdy juga mengusulkan peneliti agar mengunjungi secara langsung makam Todilaling adalah Mara'dia/Raja pertama di Kerajaan Balanipa.

- H. Alimuddin (Guru) banyak menceritakan sejarah munculnya pertama kali Pattu'du' Kumba dari berbagai versi dan Beliau juga memperlihatkan kostum dan perhiasan Pattu'du' Kumba serta menjelaskan fungsinya masingmasing.

- M. Rahmat Muchtar (pengelolah Uwake' Culture Foundation), Beliau adalah ketua Sanggar Seni Uwake' yang banyak menceritakan tentang bagaimana proses yang telah dilalui selama revitalisasi Tari Pattu'du' Kumba berjalan, banyak hal yang mereka lalui hingga Tari Pattu'du' Kumba berhasil di revitalisasi dan pada akhirnya di tampilkan pertama kali di Festival Pesona Budaya Cakuriri setelah vakum beberapa tahun.

- Muhammd Ridwan Alimuddin (Penulis, Jurnalis, Pemerhati Budaya) untuk menceritakan sejarah kostum dan riasan wajah penari dari zaman dahulu sampai sekarang, ada juga beberapa dokumentasi lama yang didapatkan peneliti melalui Beliau.

- Siti Adila (Guru), Beliau adalah penari Pattu'du' Kumba pada acara Pekan Budaya pertama di Karebosi pada tahun 2019, Ibu Siti Adila yang telah mengajarkan gerakan Pattu'du' Kumba kepada anggota Sanggar Seni Uwake', Beliau banyak menceritakan pengalamannya selama menjadi penari Pattu'du Kumba baik suka maupun duka, Ibu Siti Adila masih sangat ingat hal yang paling menyakitkan waktu itu adalah pada saat akan mengenakan anting yang pada tahun 90-an anting/Dali masih terbuat dari baut yang ukurannya lumayan besar sehingga pada saat dimasukkan ke telinga sering kali telinga penari berdarah.

- Muh Naim Sail (wiraswasta), banyak menceritakan tentang sejarah Pattu'du kumba dan sejarah Polewali Mandar, melalui Beliau Peneliti banyak mendapatkan informasi mengenai pelantikan Raja/Pemangku Adat.

Mereka adalah orang-orang yang dianggap mampu untuk memberikan keterangan mengenai seluk-beluk Pattu' $d u$ ' Kumba dan proses revitalisasinya.

4. Dokumentasi

Dalam penelitian ini, peneliti melakukan teknik pengumpulan data dengan cara pendokumentasian dilapangan serta mencari dokumen-dokumen yang ada untuk melengkapi data-data peneliti. Selain 
dokumen-dokumen yang ada di sanggar, dilakukan juga perjalanan menuju makam Raja Balanipa pertama untuk menyaksikan jejak proses pemakaman posisi penari Pattu'du saat Raja Todilaling dimasukkan keliang lahad.

Menurut Sugiono (2008: 82) dokumen adalah catatan-catatan peristiwa yang telah lalu, yang bisa berbentuk tulisan, gambar, atau karya monumental seseorang. Teknik dokumentasi digunakan untuk melengkapi data-data yang didapat dari hasil observasi dan wawancara. Pengumpulan data melalui dokumentasi berupa foto-foto dan rekaman hasil wawancara dengan narasumber.

\section{E. Teknik Analisis Data}

Analisis data dilakukan dari setiap bagian yang ditemukan. Data yang diperoleh tersebut dari study pustaka, observasi, dan wawancara dianalisis dan secara kualitatif sesuai dengan pokok bahasanya. Kegiatan ini dilakukan setelah proses pengumpulan data dan merupakan tahap analisis yang sesungguhnya. Melalui teknik analisis data ini diharapkan peneliti dapat melahirkan kesimpulan yang berkaitan dengan tujuan penelitian. Kegiatan yang dilakukan kemudian ditulis dalam suatu laporan.

\section{HASIL PENELITIAN DAN PEMBAHASAN}

\section{A. Hasil Penelitian}

Sebelum membahas terlalu dalam tentang hasil penelitian dari skripsi ini, terlebih dahulu Peneliti menjelaskan tentang latar belakang Sanggar Seni Uwake' dan gambaran umum Tari Pattu'du' Kumba secara singkat.

Sanggar Seni Uwake' Culture Foundation atau sanggar Seni Uwake' adalah sebuah lembaga nirlaba yang sejak tahun 2010 telah lahir dan baru tahun 2012 kehadirannya sudah resmi diakta notariskan, ketua pertama sanggar seni Uwake' adalah M. Rahmat Muchtar yang masih penjabat sampai saat ini. Sanggar seni Uwake' mencoba melakukan penguatan kehidupan serta programprogram pengembangan sumber daya manusia dalam bidang pendidikan, pelestarian melalui perspektif seni budaya baik yang berasal dari pemerintahan, swasta dan masyrakat. Penamaan "Uwake" pada sanggar seni Uwake' berasal dari bahasa Mandar yang berarti "akar" maka dari itu dalam berkesenian sanggar ini tetap menjujung tinggi yang dikatakan budaya dan tradisi yang ditinjaudari akarnya atau dapat dikatakan keaslian dari kesenian itu sendiri (Wawancara, M. Rahmat Muhtar, J1 Sultan Hasanuddin, 4 November 2019).

Pattu'du' Kumba adalah tarian yang berasal dari Sulawesi Barat, kata $T u$ 'du' itu sendiri adalah berasal dari bahasa Mandar yang artinya Tari dan $P a$ adalah pelaku tari, jadi Pattu'du adalah penari sedangkan Pattu'du' adalah sebuah gerakan dari pelaku yang berbusana adat daerah dan dipandu oleh lagu serta diiringi gendang dan gong atau alat kesenian lainnya. Kata Kumba berasal dari bahasa Mandar kuno yang diyakini artinya adalah pembukaan atau saling buka membuka yang memperlihatkan kerendahan hati seseorang dan tidak saling menyombongkan diri, arti lain dari kata Kumba adalah ungkapan rasa rindu dari kekasih. Ciri khas gerakan Pattu'du' Kumba ada pada tarikan kipas, lirikan mata penari senantiasa melirik pada ayunan tangan dan tarikan kipas.

Pattu'du' Kumba dalam setiap pementasannya, selalu diiringi dengan alat musik yaitu 2 buah Gendang dan 1 Gong, alat musik digunakan sebagai penyeimbang gerak tarian. Alat musik dimainkan oleh pemain musik pria, pada acara Pelantikan Raja tari Pattu'du' kumba dimainkan pada saat Raja akan dilantik kemudian tarian akan berakhir pada saat pelantikan juga selesai. Durasi yang digunakan tidak menentu, ada dua versi Pattu'du' kumba jika memerlukan durasi yang panjang yaitu yang pertama musik diulang sebanyak dua kali atau yang kedua syair tarian yang diulang menjadi dua kali. 
Radawati, Rahma M, Andi Padalia. Revitalisasi Tari Patu'du' Kumba Oleh Sanggar Seni Uwake' Di Kecamatan Tinambung Kabupaten Polewali Mandar.

Pattu'du' yang ada pada awalnya adalah merupakan sebuah persembahan kepada sesuatu yang dipuja, olehnya itu Pattu'du' pada masa sebelum adanya Tomakaka (orang yang berkemampuan) di Mandar, tari yang ada hanyalah tari Cakkuriri yang dilakukan oleh para lelaki dan perempuan sebagai tari massal karena pada masa itu penduduk di kawasan Mandar masih menganut paham Animisme dan Dinamisme, dan pada masa Tomakaka muncul tarian Losa-losa, Sababar dan Salonreng yang hanya diikuti dengan gendang alat kesenian lainnya tanpa lagu dan pada perkembangan selanjutnya lahir tari Sarawadang, Kumba, dan Sore yang sudah diiringi dengan lagu dan pada masa itu Islam belum masuk ke Mandar, agama yang dianut penduduk waktu itu adalah agama Hindu atau Budha (Asdy, 2019: 44).

Menurut Bapak Ahmad Asdy (wawancara, Tinggas-tinggas: 02 September 2019) Pattu'du' Kumba adalah tarian yang berasal dari tari persembahan, diketahui pada zaman kerajaan dan pengaruh agama Islam belum masuk di tanah Mandar. Setiap orang mempercayai bahwa mereka harus mengetahui Tari Pattu'du' Kumba dan beberapa Pattu'du' lainnya yang ada di Mandar untuk melakukan sebuah persembahan kepada Dewa atau roh nenek moyang.

1. Proses Revitalisasi Tari Pattu'du' Kumba oleh Sanggar Seni Uwake' Di Kecamatan Tinambung Kabupaten Polewali Mandar

M. Rahmat Muchtar adalah ketua Sanggar Seni Uwake' yang menjabat dari awal terbentuknya Sanggar Uwake' hingga saat ini, yang berperan penting dalam proses revitalisasi Tari Pattu'du Kumba. Beliau juga termasuk pemusik Pattu'du' Kumba yang selalu ikut mengiringi kemanapun Pattu'du Kumba di pentaskan. Bapak M. Rahmat Muchtar bersama dengan ibu Siti Adila memperkenalkan kembali tari Pattu'du' Kumba kepada anggota Sanggar Seni Uwake'. Sebelumnya ibu Siti Adila adalah penari Pattu'du' Kumba diera 90-an Beliau beserta 13 (tiga belas) orang lainnya yang telah menampilkan Pattu'du' Kumba pada acara Pekan Budaya pertama di Karebosi pada tahun 1990. Ibu Siti Adila adalah penari di tahun 90 -an yang satusatunya tinggal di daerah Tinambung satu lokasi dengan Sanggar Seni Uwake, sedangkan ke 13 (tiga belas) orang penari lainnya telah terpisah-pisah ke daerah perantauan mereka masing-masing. Ibu Siti Adila-lah yang diamanahkan untuk mengajarkan Gerak

\section{a. Gerak}

Gerakan pada Tari Pattu'du' Kumba cenderung lebih tenang, gerakan penari menggambarkan perasaan kerinduan sesuai dengan arti yang terkandung didalam tarian yaitu perasaan rindu terhadap kekasih. Sehingga menciptakan ruang gerak yang kecil, kecil dalam artian dimana lengan diangkat seperlunya sehingga tidak perlu memperlihatkan ketiak, pandangan penari tetap berada pada titik fokus gerakan tangan dan kipas.

Wujud gerakan yang mengalami perubahan adalah pada ragam Mioro Mi'undur, yaitu pada gerakan menunduk hingga kepala hampir menyentuh mata kaki, ini dikarenakan dari SDM adanya paham bahwa Pattu'du' Kumba adalah tari persembahan atau penghormatan terhadap roh nenek moyang, atau persembahan terhadap Raja-raja. Sehingga diyakini gerakan menunduk adalah gerakan yang paling tepat untuk memasukkan makna yang terkandung dalam tarian, yang dahulu pada gerakan ini hanya menunduk setengah badan saja, adanya juga penambahan gerak keluar masuk panggung, jika pada zaman kerajaan Tari Pattu'du' Kumba ditarikan langsung di dalam tempat pertunjukan, maka diperkembangannya Pattu' $d u$ ' kumba ditambahkan gerakan keluar masuk panggung sebagai bentuk kebutuhan pertunjukan dan lebih memperindah saat akan dimulai dan berakhirnya tarian. Perubahan gerak hanya terjadi pada Ragam 
Mioro' Mi'undur. Selain itu pada ragam yang lainnya seperti Ragam Uru'-Urunna, Malleppe' Sipi', Appe' Mata Angin, Mioro' Mijaramming, Sau Dhomai, dan Millamba Milai tidak mengalami perubahan dari segi gerakan maupun musiknya.

\section{b. Pelaku Tari}

Pelaku tari adalah penari atau orang yang membawakan suatu tarian. Dalam pertunjukan Tari Pattu'du' Kumba para penari dengan gerakannya yang lemah lembut sesuai dengan irama musik pengiring. Gerakan di dalam tarian ini lebih didominasi dengan gerakan tangan yang memainkan kipas dan gerakan kaki yang melangkah secara perlahan.

c. Musik Iringan

Pattu'du Kumba diiringi oleh dua buah Ganrang (gendang) dan satu Ta'bilowe (Gong). Semua jenis Pattu'du yang ada di Mandar menggunakan alat kesenian yaitu dua Gendang dan satu buah Gong kecuali Pattu'du' Denggo yang menggunakan alat musik yang disebut Rawana (Rebana). Dapat kita lihat pada proses latihan Sanggar Seni Uwake' menggunakan iringan musik Gendang lebih dari dua dan satu buah Gong. Semakin banyak gendang yang digunakan maka akan semakin enak kedengarannya $s i$ indo indo $i$ (sebutan teknik gendang variasi Mandar).

\section{d. Kostum dan Perhiasan Penari}

Busana bagi manusia pada hakekatnya adalah untuk melindungi tubuh dari terpaan panas dan dingin di samping itu pula untuk mempercantik diri bagi wanita dan membuat semakin anggun dalam penampilan bagi orang-orang Mandar. Selain itu, kostum dikenakam penari untuk mempertunjukkan karya tari yang dimana busana tari harus enak dipakai, enak dilihat, dan tidak mengganggu gerak penari. Fungsi utama dari busana dalam karya tari atau suatu pertunjukan tari adalah memperjelas tema tari, membantu menghidupkan karakter dan peran tari, membantu ekspresi penari dalam melakukan gerak tari, dan memberikan nilai tambah pada segi keindahan dan etika. Berikut adalah busana dan perhiasan Pattu'du' Kumba:
1) Bayu Pasangan
2) Lipa' A'di Diratte
3) Kawari
4) Tombi Tallu/Tombi A'di
5) Tombi Sare-sare
6) Tombi Suku-suku atau Tombi Diana
7) Tombi Lamber
8) Tombi Tungga'
9) Jima' Saletto'
10) Dali atau Subang
11) Gallang Balle
12) Sunting atau Bunga-bunga

e. Riasan Wajah Penari

Tata rias adalah seni penggunaan alatalat makeup pada wajah penari. Rias di dalam tari tidak hanya bertujuan untuk menjadikan penari menjadi cantik, tapi juga untuk membantu pertunjukan karya tari lebih baik.

Menurut Bapak Muhammad Ridwan Alimuddin (Wawancara, Pambusuang: 3 September 2019). Riasan wajah Pattu'du' sangat sederhana bahkan dulu penari hampir seperti orang yang tidak mengenakan alat makeup sama sekali, ini disebabkan minimnya alat makeup pada zaman itu. Setelah memasuki tahun 90-an makeup penari meningkat, menjadi semakin lebih dipertajam dan lebih kelihatan memakai makeup, selain dari semakin berkembangnya seni makeup. Makeup juga menjadi peran penting dalam tarian ini dikarenakan adanya kebutuhan pasar atau riasan wajah penari juga menjadi salah satu daya tarik penonton.

\section{f. Properti}

Properti yang digunakan dalam tarian ini yaitu menggunakan kipas dan selendang, dari dulu property Tari Pattu'du' Kumba tidak mengalami perubahan, karena masyarakat masih menganggap bahwa kipas dan selendang sebagai bagian dari perlengkapan tari yang tak harus dihilangkan. Perubahan yang 
Radawati, Rahma M, Andi Padalia. Revitalisasi Tari Patu'du' Kumba Oleh Sanggar Seni Uwake' Di Kecamatan Tinambung Kabupaten Polewali Mandar.

terjadi hanya pada ujung kain selendang yang dimana semua jenis Pattu' $d u$ ' Mandar dan orang yang mengenakan baju Pattu' $d u$ ' selamanya memakai selendang yang berbentuk segitiga panjang atau segi empat panjang yang masing-masing di ujungnya terdapat hiasan yang terdiri dari duplikat ikan, burung atau hewan lain yang disebut Kipa-kipa dan dapat dipakai oleh semua golongan.

\section{g. Durasi}

Durasi Pattu'du Kumba terbilang durasi yang cukup lama, dan tidak memiliki perubahan pada durasinya. Tarian ini dipentaskan selama kurang lebih 15 sampai 20 menit, salah satu penyebab yang membuat durasi terbilang lama karena Pattu'du' Kumba memiliki syair yang cukup panjang dan cara penyampaiannya pun dipenggal-penggal sehingga memperpanjang durasi, selain itu Pattu'du' Kumba dipentaskan pada acara-acara kerajaan seperti pelantikan Raja, Sunatan, Pelattigiang (malam pacar), dan pernikahan. Pada saat proses pelantikan Raja, Sunatan, Pelattigiang (malam pacar) ataupun pernikahan berlangsung saat itu pula Pattu'du' Kumba dipentaskan hingga proses acara penting tersebut selesai. Biasanya dalam setiap pementasan Pattu'du' Kumba memiliki 2 (dua) sampai 3 (tiga) penyanyi, ini dikarenakan nada syair Pattu'du Kumba terlalu tinggi dan mendayu-dayu sehingga ketika penyanyi yang satunya kewalahan atau tidak mencapai tangga nadanya, maka akan segera disambung oleh penyanyi yang satunya lagi

\section{B. Pembahasan}

Pattu'du' Kumba sudah ada sejak beberapa tahun lalu sebelum zaman kerajaan belum ada di tanah Mandar, Pattu'du' Kumba saat itu di pertunjukkan pada upacara-upacara adat atau upacara persembahan kepada roh nenek moyang dari masa ke masa Pattu'du' Kumba mengalami perubahan fungsi pertunjukannya tetapi tidak mengurangi makna yang terkandung di dalam tarian. Kemudian setelah masuknya zaman kerajaan Pattu'du' Kumba dipentaskan pada acara-acara penting kerajaan, seperti Pelantikan Raja, Sunatan, Pelattigiang (malam pacar), dan juga pernikahan anak Raja.

Menurut Naim melalui (Wawancara via telfon 20 Oktober 2019) mengatakan:

'Fungsi terakhir Pattu'du' Kumba dipentaskan pada saat Pelantikan Raja/Pemangku Adat ke 55 yaitu Raja Andi Bau Arifin Malik pada tahun 2008. Setelah pelantikan Raja ke 55 tidak pernah lagi ada pertunjukan Pattu'du' Kumba hingga kurang lebih 10 tahun ke depan. Meskipun saat ini Polewali Mandar telah di pimpin oleh pemerintahan setempat, tetapi struktur adat kerajaan masih berjalan tetapi sudah tidak memerintah seperti dahulu. Pergantian atau pergeseran jabatan raja atau Mara'dia akan dilakukan lagi jika Raja sebelumnya telah meninggal dunia".

1. Proses Revitalisasi Tari Pattu'du' kumba oleh Sanggar Seni Uwake' di Kecamatan Tinambung Kabupaten Polewali Mandar.

Selain mengikuti workshop dan dipertontonkan berbagai video pertunjunkan seperti tentang tari tradisional, tari modern hingga musik, proses revitalisasi juga dilakukan dengan tahapan pertama memperkenalkan kembali Tari Pattu'du' Kumba terhadap anggota Sanggar, ini bertujuan agar ketika Pattu'du' dipelajari kembali tariannya bukan hanya gerakannya saja yang dapat mereka ketahui tetapi juga fungsi dan makna yang tersirat di dalamnya. Kemudian tahapan yang kedua adalah mempelajari kembali gerakan Pattu'du' Kumba yang diajarkan langsung oleh Siti Adila, sebagai pelaku Pekan Budaya pertama yang ada di karebosi pada tahun 1990 beliau, selain Ibu Siti Adila ada juga Uci yang ikut serta dalam melatih 
anak-anak sanggar (Wawancara Siti adila, Sepang: 8 September 2019).

Tidak hanya sampai disitu, setelah anak-anak Sanggar mengetahui tari Pattu'du' Kumba mereka dibuatkan jadwal untuk setiap minggu minimal sekali mereka latihan agar pada saat dipentaskan mereka tidak kaku dalam bergerak. Selain di Sanggar, ketua sanggar dan staf-staf Sanggar lainnya lebih jeli dalam melihat peluang agar Proses revitalisasi yang mereka lakukan terhadap Pattu'du Kumba tidak hanya di cukup dipertontonkan di lingkungan sekitar, akan tetapi bagaimana caranya mereka bisa membawa tarian ini di pentaskan pada acara-acara tertentu. Sanggar Seni Uwake melakukan proses revitalisasi terhadap Pattu'du Kumba di tahun 2016, dan pada tahun 2017 di pertunjukan pada acara Pesona Cakuriri 2-4 Oktober 2017.

Bukan hanya Pattu'du' Kumba yang berusaha direvitalisasi kembali oleh Sanggar Seni Uwake', tetapi juga tariantarian tradisional lainnya yang ada di Polewali Mandar. Seperti Pattu'du' Denggo dan lain-lain, Pattu'du' Denggo belum pernah dipentaskan selama proses revitalisasi tetapi anggota sanggar tetap rutin latihan sekali atau dua kali dalam satu minggu meskipun tidak sedang akan dilakukan pementasan.

Proses Revitalisasi Tari Pattu'du' Kumba yang dilakukan Sanggar Seni Uwake' adalah sebagai berikut:

- Menelusuri jejak penari terdahulu.

- Menelusuri jejak Tokoh Budayawan yang mengerti tentang seluk beluk Tari Pattu'du'Kumba.

- Perekrutan anggota sanggar dari kalangan pelajar SMP/SMA.

- Mengikutsertakan anggota dalam kegiatan-kegiatan yang bersifat kesenian tradisional misalnya workshop kesenian tradisional atau khususnya workshop Tari Pattu'du' Kumba.

- Dipertontonkan video pertunjukan tari maupun musik tradisional.
- Memperkenalkan kembali seluk beluk Tari Pattu'du' Kumba kepada anggota sanggar.

- Anggota Sanggar Seni Uwake' diajarkan kembali gerak Tari Pattu'du' Kumba.

- Dibuatkan jadwal latihan 2-3 kali seminggu.

2. Faktor Yang Mempengaruhi Revitalisai Tari Pattu'du' Kumba oleh Sanggar Seni Uwake'

Revitalisasi adalah upaya menghidupkan kembali sesuatu yang eksistensinya masih berarti dan dengan demikian eksistensi tersebut perlu dijaga dan dikembangkan, dari penjelasan tetang revitalisasi ada beberapa faktor yang mempengaruhi terjadinya revitalisasi oleh sanggar seni Uwake' terhadap Pattu'du' Kumba. Faktor yang pertama adalah adanya kesadaran untuk berkesenian tradisional, menampilkan beberapa tari ataupun pertunjukan musik tradisional yang artinya adalah di zaman yang serba modern sekarang sudah sangat jarang kita jumpai kesenian tradisional dalam setiap acara kesenian. Melalui kesadaran tersebut sanggar seni Uwake' mengadakan revitalisasi terhadap Pattu'du' Kumba agar tarian ini tidak hilang ditengah persaingan kesenian yang serba modern.

Faktor yang lainnya adalah adanya kesadaraan tentang bagaimana dengan nasib para generasi penerus jika sepuluh atau dua puluh tahun lagi tari Pattu'du' khusunya Pattu'du Kumba hanya tinggal sejarah masa lampau yang mereka tidak ketahui. Maka Pattu'du' Kumba akan hilang dimakan zaman, akan tetapi dengan adanya bentuk revitalisasi yang dilakukan oleh sanggar seni Uwake' ini dapat melahirkan generasi-generasi baru yang bisa saja kelak merekalah yang akan mengajarkan kembali kepada generasi selanjutnya, baik itu dari segi gerak Pattu'du, serta fungsi dan makna apa saja yang terkandung didalamnya. 
Radawati, Rahma M, Andi Padalia. Revitalisasi Tari Patu'du' Kumba Oleh Sanggar Seni Uwake' Di Kecamatan Tinambung Kabupaten Polewali Mandar.

Faktor pendukung revitalisasi Tari Pattu'du' Kumba beragam, mulai dari SDM yang memadai serta adanya dukungan dari Tokoh Budayawan setempat serta dukungan dari pemerintah setempat dan juga ketersediaan tempat untuk proses latihan Sanggar Seni Uwake’ salah satunya adalah latihan tari tradisional Pattu'du Kumba. Adanya pula dukungan dari pemerintah setempat, meskipun bukan dukungan materi tetapi dukungan spirit dan pengadaan alat-alat musik serta dukungan fasilitas seperti tempat latihan aula desa diizinkan dipakai selama proses latihan Sanggar. Faktor pendukung internal adalah: adanya SDM yang memadai, dan yang termasuk ke dalam Faktor pendukung eksternal adalah: adanya dukungan dari Tokoh Budayawan setempat dan dukungan dari masyarakat setempat, ketersediaan tempat untuk proses latihan yang dilakukan oleh anggota Sanggar Seni Uwake' yaitu di Aula Pemerintahan Desa setempat, pengadaan alat musik oleh Pemerintah setempat untuk Sanggar Seni Uwake'.

Faktor penghambat adalah hal-hal yang mempengaruhi suatu kegiatan bisa berjalan tidak lancar, lambat atau tertahan. Selain faktor pendukung dalam proses revitalisasi juga memiliki faktor penghambat. Salah satu faktor penghambat adalah adanya kesibukan masing-masing dari anggota Sanggar Seni Uwake', sehingga pada saat latihan tidak jarang ada beberapa penari atau pemusik yang berhalangan hadir. Faktor lainnya adalah tidak adanya kostum dan perhiasan penari yang dimiliki oleh Sanggar Seni Uwake', sehingga pada saat tari akan dipertunjukkan mereka harus menyewa kostum dari luar. Selama proses Revitalisasi dilakukan tidak banyak kendala yang ditemui, semua yang dibutuhkan sedikit banyak bisa diadakan seperti kesibukan masing-masing anggota saat akan latihan atau mengikuti workshop Pattu'du' Kumba sesekali bisa diakali dengan mengubah jadwal latihan atau meminta pengertian waktu terhadap masing-masing anggota, tetapi hal tersebut tetap saja menjadi salah satu faktor penghambat proses revitalisasi. Faktor penghambar internal dari proses revitalisasi Tari Pattu'du' Kumba adalah kesibukan masing-masing dari anggota Sanggar Seni Uwake', sehingga pada saat latihan tidak jarang ada beberapa penari atau pemusik yang berhalangan hadir. Faktor penghambat eksternalnya adalah: tidak adanya kostum dan perhiasan penari yang dimiliki oleh Sanggar Seni Uwake', sehingga pada saat tari akan dipertunjukkan mereka harus menyewa kostum dari luar.

\section{Saran}

Berdasarkan pembahasan dan kesimpulan yang telah dikemukaan sebelumnya, maka ada beberapa saran yang penulis sampaikan yaitu sebagai berikut:

1. Diharapkan kepada pemerintah kota Kabupaten Polewali Mandar agar lebih memperhatian dan dukungan terhadap lembaga seni atau sanggar seni yang memiliki upaya untuk mempertahankan kelestarian kesenian tradisional.

2. Penelitih sangat berharap agar Sanggar Seni Uwake' terus menjaga kelestarian Pattu'du' Kumba agar tak hilang di telan zaman yang semakin modern seperti sekarang ini.

3. Peneliti sangat berharap agar semua lapisan masyarakat ikut membantu menjaga dan melestarikan budaya tradisional kita.

4. Tari tradisi diharapkan akan tetap ada dan dipertunjukkan, terutama tari Pattu'du' Kumba.

\section{DAFTAR PUSTAKA}

\section{Sumber Tercetak}
Asdy, Ahmad. 2006. Jelajah Budaya Mengenal Kesenian Mandar. Yayasan Maha Putra Mandar. 
Jurnal Pakarena, Vol 4 No 1, Juli 2020, hlm 14-26. 2016. Kumpulan Sejarah

Lagu-lagu Nostalgia Mandar. Yayasan Mahaputra Mandar.

2019. Mengenal Pattu'du'

Tradisional Mandar. Yayasan Maha Putra Mandar.

Departemen Pendidikan dan Kebudayaan.

1989. Kamus Besar Bahasa

Indonesia. Jakarta. Balai Pustaka

Latief, Halilintar. 2016. Metode Penelitian Kualitatif. Yogyakarta: Padat Daya.

Moleong, Lexy J. 2006. Metode Penelitian Kualitatif . Bandung: Rosdakarya.

Sugiono. 2008. Metode Penelitian Bisnis. Bandung: Alfabeta

\section{Webtografi}

Bungaria, Sri. 2013. Studi Morfologi Tari Patuddu Kumba di Kecematan Tinambung Kabupaten Polewali Mandar dengan Sistem Notasi Laban. (skripsi Fakultas Seni dan Desain Program Studi Sendratasik Universitas Negeri Makassar)

Indahdkurn dan Mushangga. 2018. Tari Tradisional Terbagi Menjadi Tiga. Brainly.https://brainly.co.id/tugas/1 4934436

Lutfiyana, Emma. 2015. Eksistensi Tari Lawet di Kabupaten Kebumen. (skripsi Fakultas Bahasa dan Seni Program Studi Pendidikan Seni Tari Universitas Negeri Yogyakarta)

Padalia, Andi.2002.Tari Pattudduk Suatu Kajian Antropologi Seni Tentang Pergeseran Orientasi Nilai Dari Sakral Ke Profan Di Tinambung Polmas.(Tesis Program Pasca Sarjana Universitas Negeri Makassar). 